\title{
Thermal Performance of Cooled Tips in A High-Pressure Turbine Blade
}

\author{
E. Maha Vishnu \\ Assistant Professor, \\ Department of Aeronautical Engineering \\ Bharath Institute of Higher Education and Research, \\ Chennai
}

\author{
P. S. Mohanasaravanan \\ Assistant Professor, \\ Department of Aeronautical Engineering \\ Bharath Institute of Higher Education and Research, \\ Chennai
}

\author{
R. Manikandan \\ Assistant Professor, \\ Department of Aeronautical Engineering \\ Bharath Institute of Higher Education and Research, Chennai
}

\begin{abstract}
In order to obtain better life and good thermal performance of the blade tip, it is necessary to increase the aerodynamic efficiency of the blade. Even though process of cooling is efficient with existing methods it is mandatory to improve the blade design to decrease the pressure drop without affecting the overall efficiency. This paper intends to improve the turbine blade life and also to reduce maintenance cost by designing and analysing various blade tip configurations. They thermal performance of cooled blade tips are analyzed and compared. By doing this a better configuration can be suggested for future blade designs to have reliable blade even at elevated temperatures.
\end{abstract}

Keywords - Tip configurations, cooling holes, thermal performance.

\section{INTRODUCTION}

In a high-pressure turbine rotor, tip clearances between rotating turbine blades and casing are necessary to prevent rubbing. The difference in pressure between the blade pressure and suction sides drives leakage flow across the tip of the blade through this clearance gap. This tip-leakage flow can cause excessively high metal temperatures and loss of material on the blade tip, resulting in a reduction of aerodynamic efficiency. Tip leakage flow is associated to three main problems,

\section{$>\quad$ Lost work \\ $>\quad$ Aerodynamic loss \\ Blade life time}

The common solution to these three problems is the reduction of tip leakage mass flow by making a smaller clearance height, which is leads to rubbing the rotor blade tip along the casing. As the rotor blade rubs along the casing, damage is caused to the casing end-wall and the rotor blade tip. Wear at the rotor blade tip causes flow disturbances and cooling hole outlets on flat tip blade are damaged. This would eventually result in inefficient cooling of the blade tip with the risk tip burnout due to excessive heat load. Additionally, the tip of the highpressure rotor blade is one of the parts that deteriorate in the gas turbine. Obtaining a good thermal performance of the blade tip to avoid local high metal temperatures represents a major challenge for turbine designers.

\section{MODELING}

2.1 GEOMETRY OF BLADE TIPS

2.1.1 Geometries of Cooled Tips

\begin{tabular}{|l|l|l|}
\hline 1 & Number of holes & 10 \\
\hline 2 & Diameter of hole & $3.6 \% \mathrm{C}$ or $8 \mathrm{~mm}$ \\
\hline 3 & Thickness of wall of SSS and Cavity & $1.35 \% \mathrm{C}$ or $3 \mathrm{~mm}$ \\
\hline 4 & Depth of wall of SSS and Cavity & $2.24 \% \mathrm{C}$ or $5 \mathrm{~mm}$ \\
\hline 5 & & \\
\hline
\end{tabular}

2.1.2 Parameters of the cascade

\begin{tabular}{|l|l|l|}
\hline 1 & Chord & $223 \mathrm{~mm}$ \\
\hline 2 & Pitch/ chord ratio & 0.83 \\
\hline 3 & Axial chord & $103 \mathrm{~mm}$ \\
\hline 4 & Inlet - flow angle & 32.5 \\
\hline 5 & Exit - flow angle & 75.6 \\
\hline 6 & Zweifel Coefficient & 0.73 \\
\hline 7 & Reynolds number & $2.3 * 10^{5}$ \\
\hline
\end{tabular}

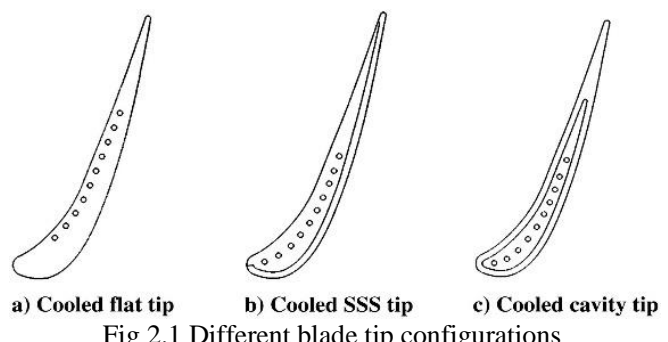

Fig 2.1 Different blade tip configurations 


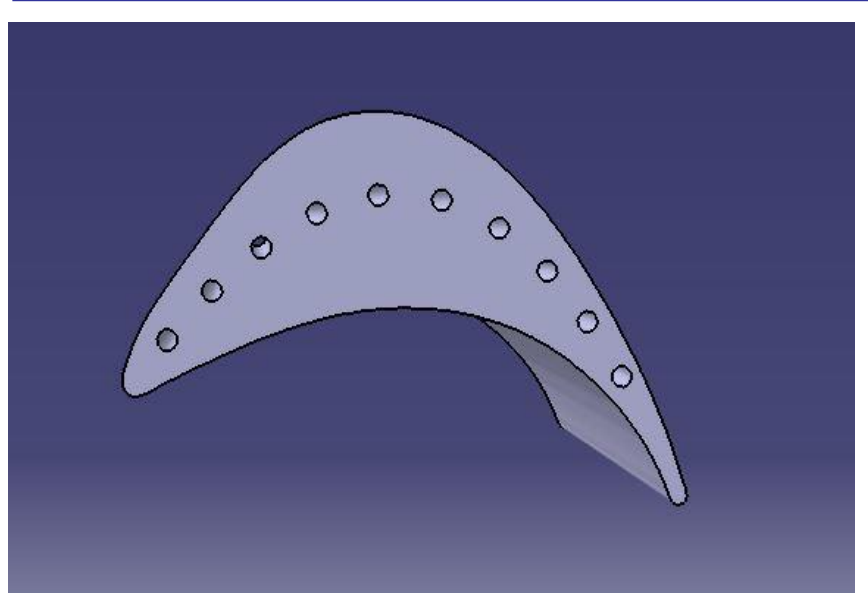

Fig 2.2 Flat Tip with Cooling Holes

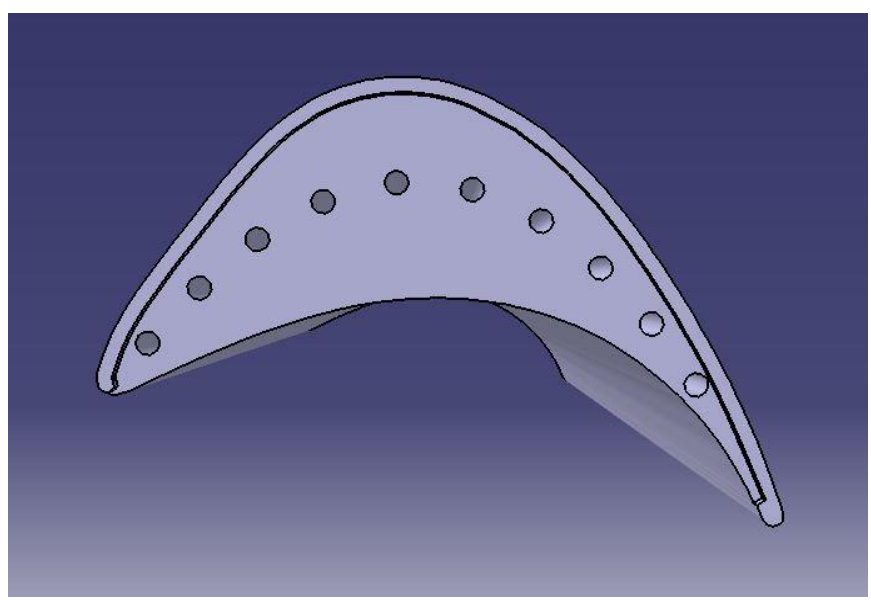

Fig 2.3 SSS Tip with Cooling Holes

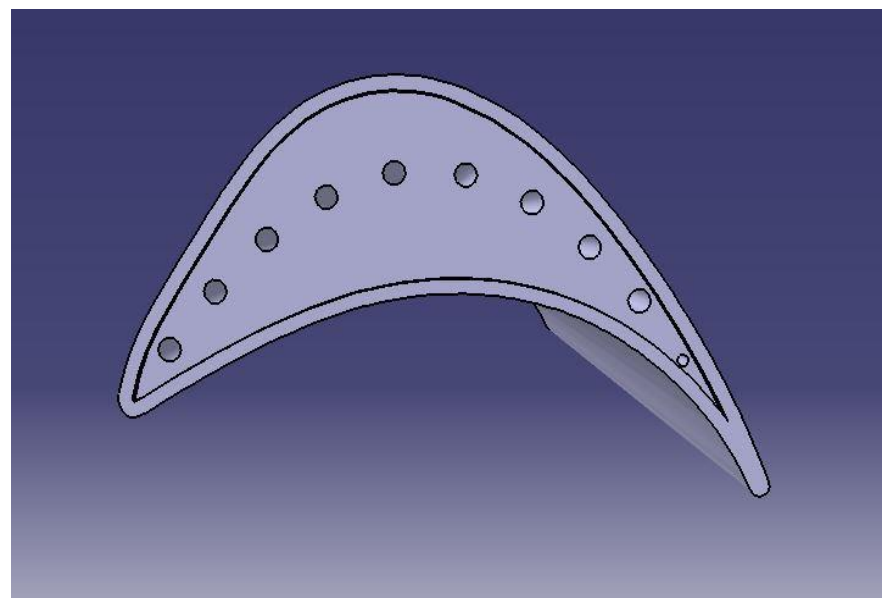

Fig 2.4 Cavity Tip With Cooling Holes

\section{ANALYSIS PARAMETERS}

\begin{tabular}{|c|l|c|}
\hline $\mathbf{1}$ & Depth of cavity & $5 \mathrm{~mm}$ \\
\hline $\mathbf{2}$ & Inlet air speed & $5 \mathrm{~m} / \mathrm{s}$ \\
\hline $\mathbf{3}$ & Inlet air temperature & $400 \mathrm{~K}$ \\
\hline $\mathbf{4}$ & Inlet Coolant Temperature & $300 \mathrm{~K}$ \\
\hline $\mathbf{5}$ & Inlet Coolant Mass flow rate & $2.6 \mathrm{~m} / \mathrm{s}$ \\
\hline $\mathbf{6}$ & Diameter of cooling holes & $8 \mathrm{~mm}$ \\
\hline $\mathbf{7}$ & Thickness of Cavity Wall & $3 \mathrm{~mm}$ \\
\hline
\end{tabular}

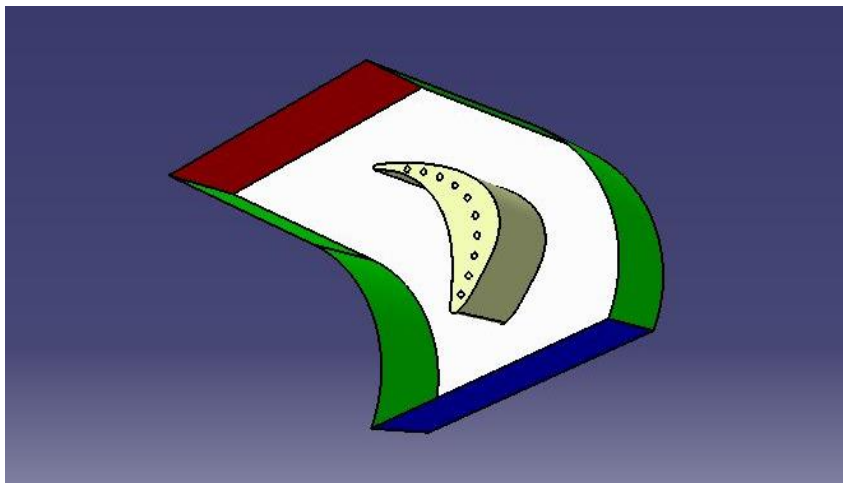

Fig 3.1 Computational Domain

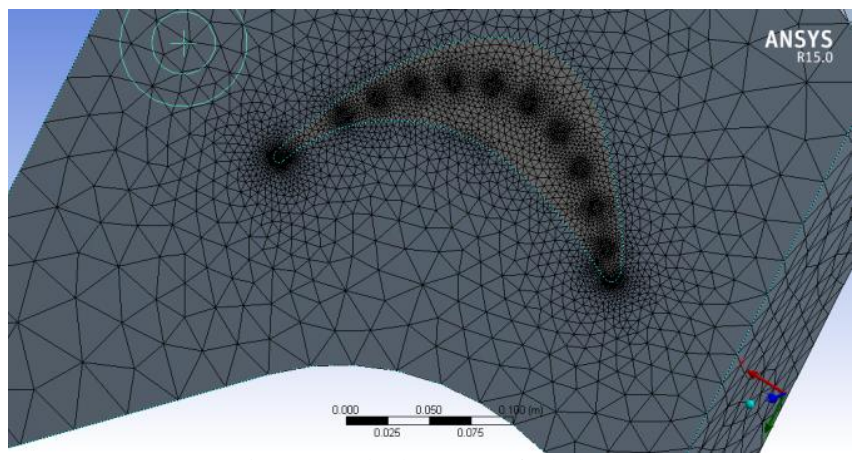

Fig 3.2 Meshed Images of Blades

\section{OBSERVATIONS}

The pressure, temperature, velocity and heat load for various configurations are observed and listed below

\subsection{Path lines of Static Temperature}

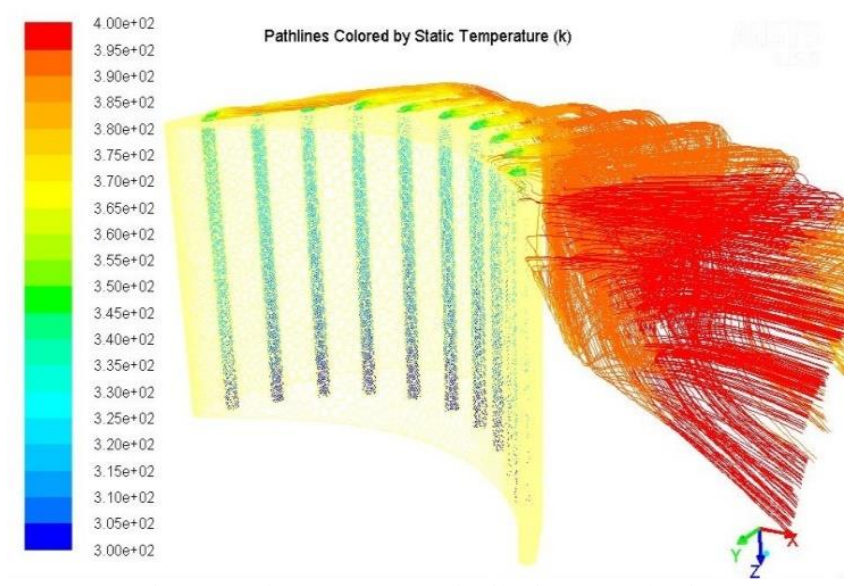

Fig 4.1 Static Temperature distribution on a Flat tip

The path lines are coloured by the non-dimensional temperature. After the coolant exits the holes, it mixes with the flow across the pressure-side inlet of the tip gap; the colour shows that the temperature increases along the flow path during this mixing process. 

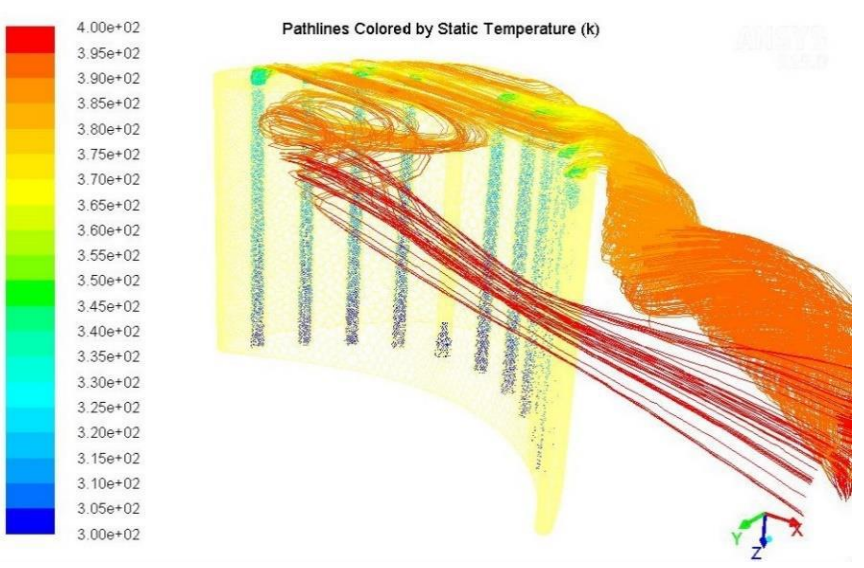

Fig 4.2 Static Temperature distribution on a SSS tip

The path lines of the coolant flow for the suction-side squealer tip are shown. The coolant flow lifts off from the floor of the tip, therefore this area is not effectively cooled. The coolant significantly changes the flow pattern over the suction-side squealer tip.

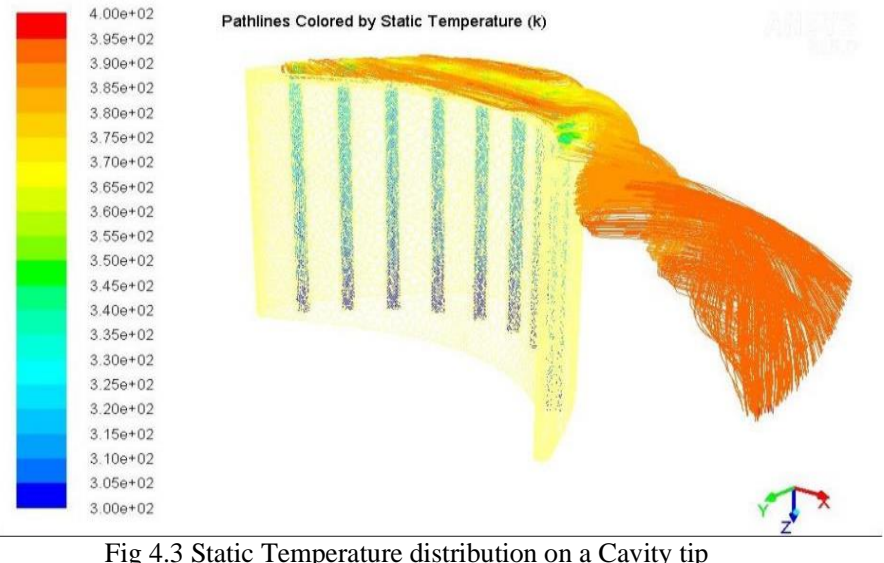

Fig 4.3 Static Temperature distribution on a Cavity tip

The path lines of the coolant flow for the cavity tip are shown. The coolant lifts off from holes but due to coolent stays in cavity for some time and get detached near trailing edge and gets mixed incoming main flow.

\begin{tabular}{|c|l|c|c|}
\hline Type of tip & \multicolumn{1}{|c|}{ Tip } & Side & Average \\
\hline Flat & $355.6169 \mathrm{~K}$ & $340.7385 \mathrm{~K}$ & $341.9091 \mathrm{~K}$ \\
\hline SSS & $348.7021 \mathrm{~K}$ & $333.7793 \mathrm{~K}$ & $335.1507 \mathrm{~K}$ \\
\hline Cavity & 347.7575 & $331.9977 \mathrm{~K}$ & $333.6060 \mathrm{~K}$ \\
\hline
\end{tabular}

Table 4.1 Comparison table of Temperature Distribution

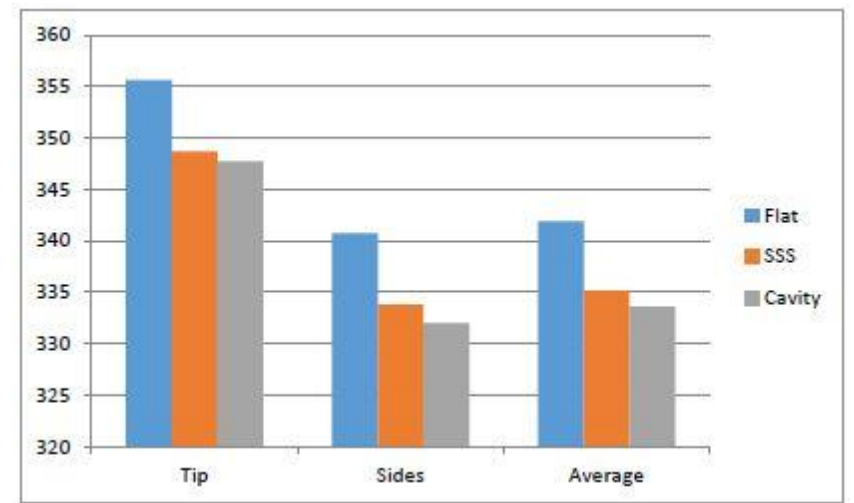

Graph 4.1 Comparison graph of Temperature Distribution

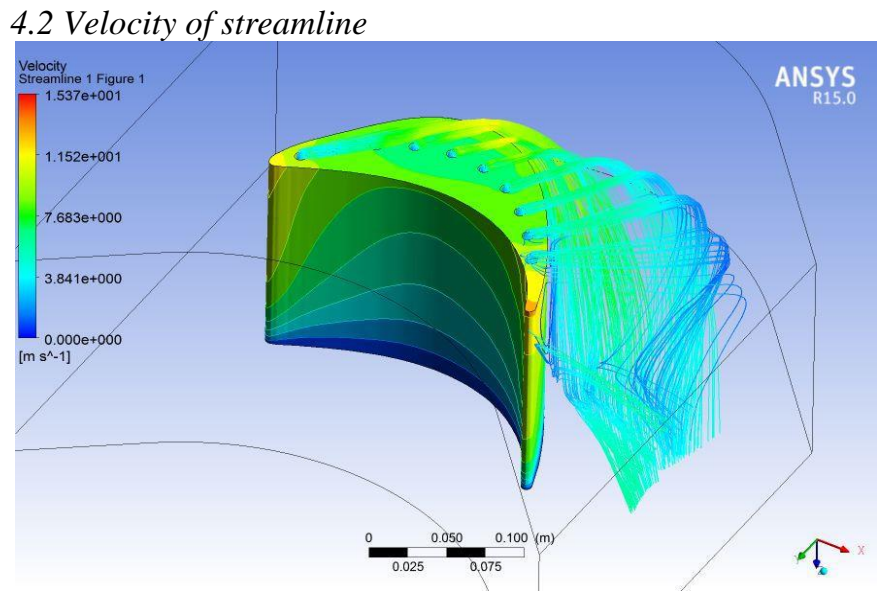

Fig 4.4 Velocity distribution on a Flat tip

The coolant leaving the cooling holes mixes with the main flow and increase its velocity.

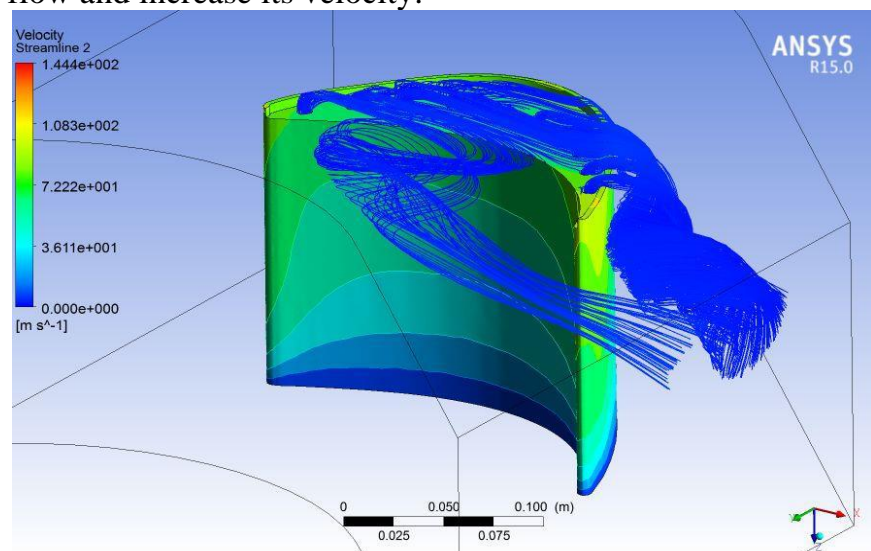

Fig 4.5 Velocity distribution on a SSS tip

For SSS blade the coolant emerging from cooling holes will be obstructed by squealer projection. Therefore small back flow of a portion of coolant will take place. After leaving blade tip it mixes with main flow and a turbulent flow is created.

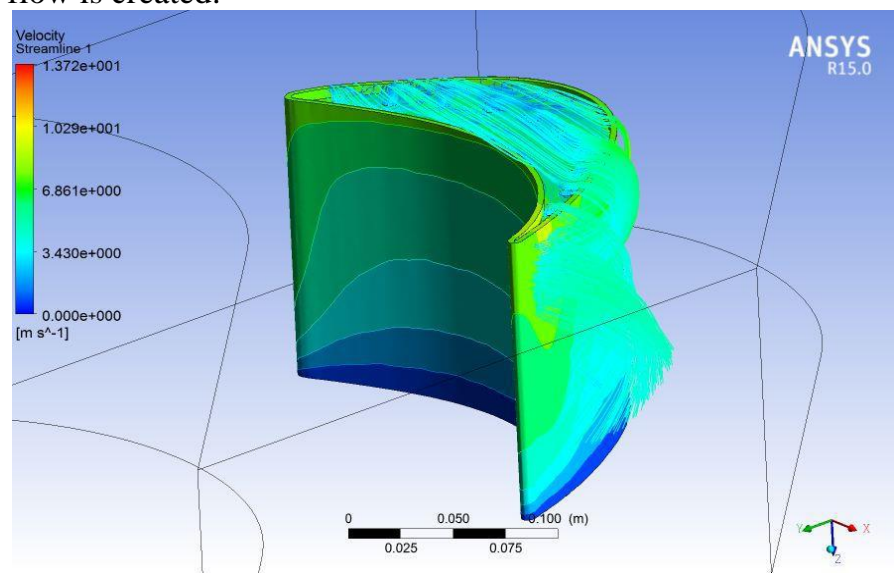

Fig 4.6 Velocity distribution on a Cavity tip

For cavity the coolant leaving the cooling holes will stay within the cavity for short time and then get detached near the trailing edge and gets mixed with main flow. 


\subsection{Contours of static temperature}
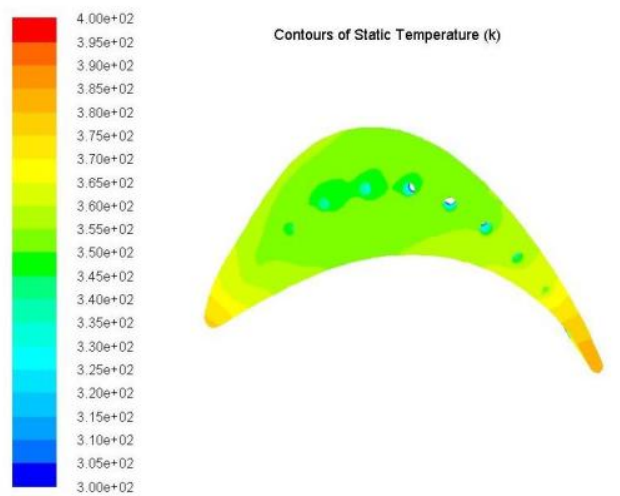

Fig 4.7 Temperature distribution on a Flat tip

For flat tip the static temperature is higher near the trailing and leading edges.
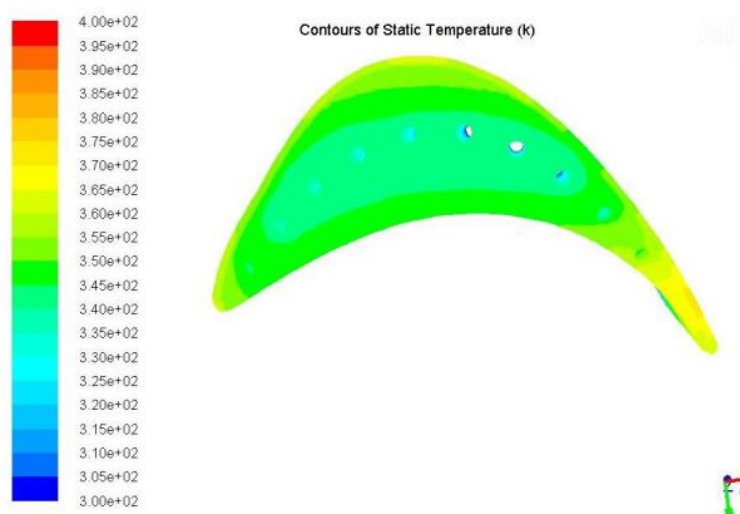

Fig 4.8 Temperature distribution on a SSS tip

For SSS blade tip the static temperature near the leading and trailing edge is high but lower than that of flat tip. The static temperature is low near cooling holes.

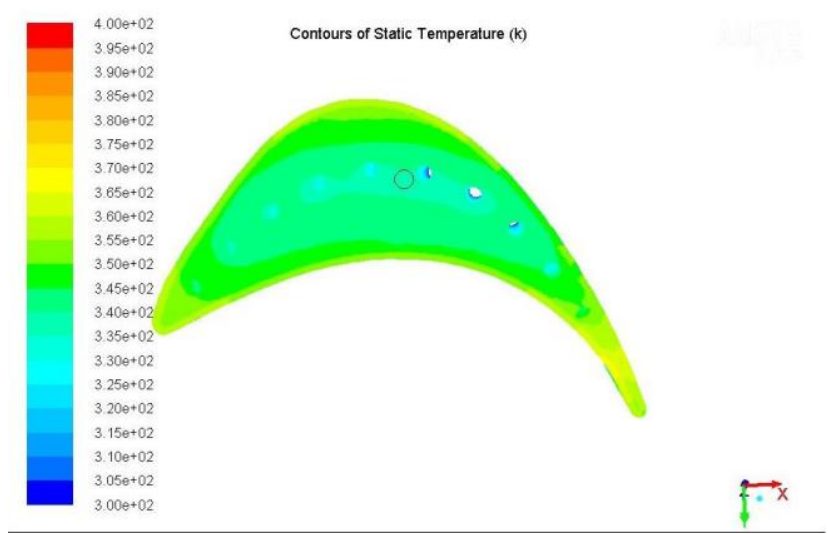

Fig 4.9 Temperature distribution on a Cavity tip

For cavity tip the static temperature is low at cavity space and near cooling holes. Static temperature at leading and trailing edge is much lower than that of flat and SSS tips.

\subsection{Contours of cooling effectiveness}

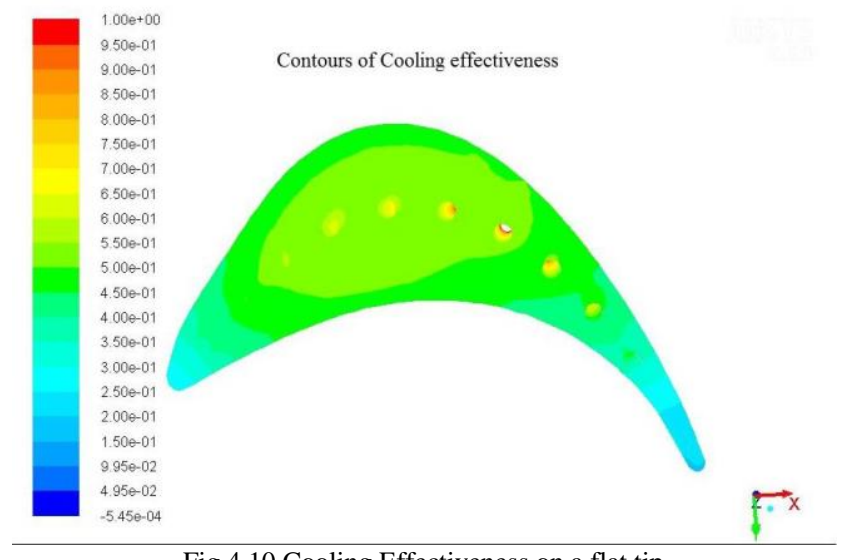

Fig 4.10 Cooling Effectiveness on a flat tip

For the cooled flat tip, the cooling effectiveness is high over the portion of the tip where the cooling holes are located. Near the leading edge and trailing edge, the cooling effectiveness is low.

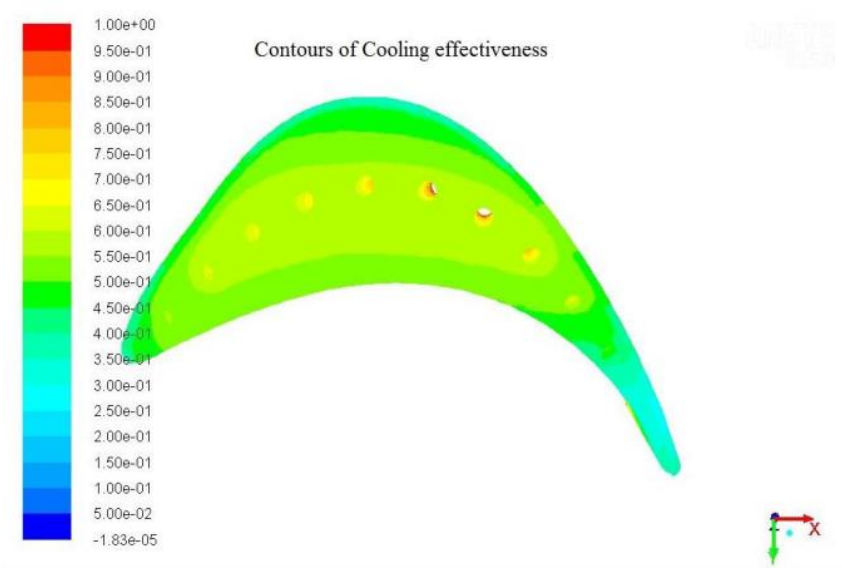

Fig 4.11 Cooling Effectiveness on a SSS tip

For SSS tip the cooling effectiveness is high near holes. The coolant also cools the top of squealer but cooling is very low near the leading edge and still worse at trailing edge.

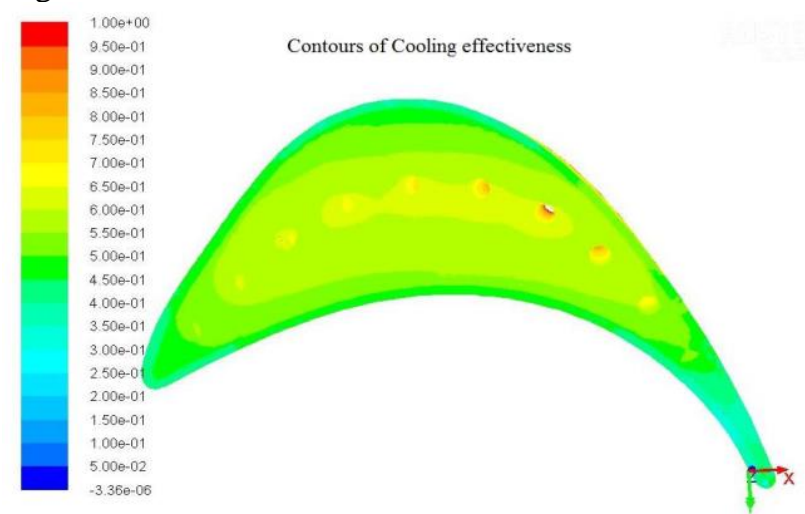

Fig 4.12 Cooling Effectiveness on a Cavity tip

For the cavity tip, the coolant cools the cavity floor and the inner surfaces of the cavity. The coolant also cools a portion of the top of the squealers, but the near-leading edge region and trailing edge region of the squealer is not effectively cooled. 


\begin{tabular}{|l|c|}
\hline Type of Tip & Cooling Effectiveness \\
\hline Flat & 0.5809 \\
\hline SSS & 0.649 \\
\hline Cavity & 0.6639 \\
\hline
\end{tabular}

Table 4.2 Comparison table of Cooling Effectiveness

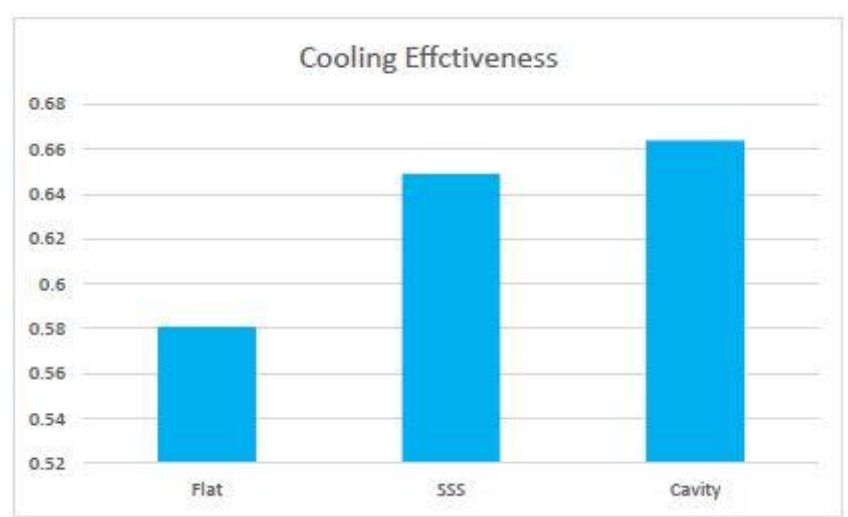

Graph 4.2 Comparison graph of Cooling Effectiveness

\subsection{Contours of heat load}

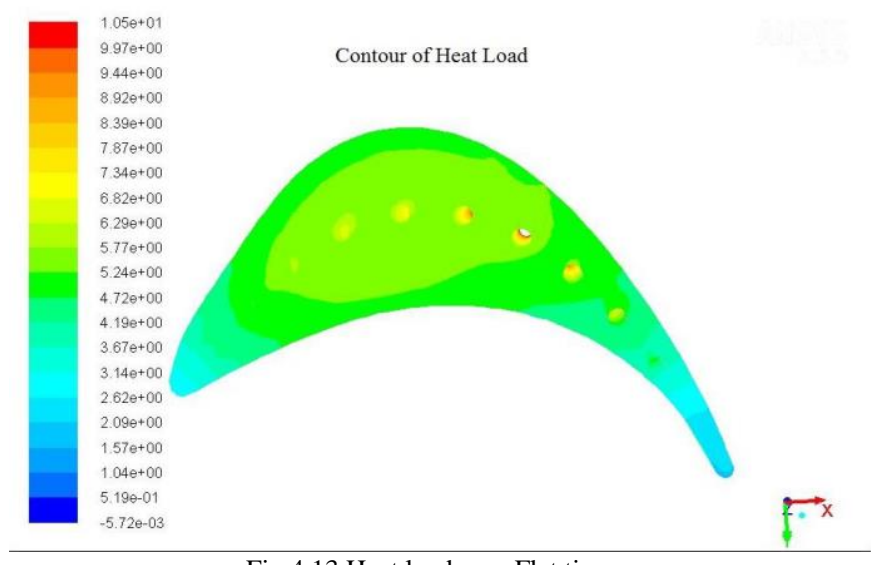

Fig 4.13 Heat load on a Flat tip

For the cooled flat tip, the coolant reduced the heat load on the tip.

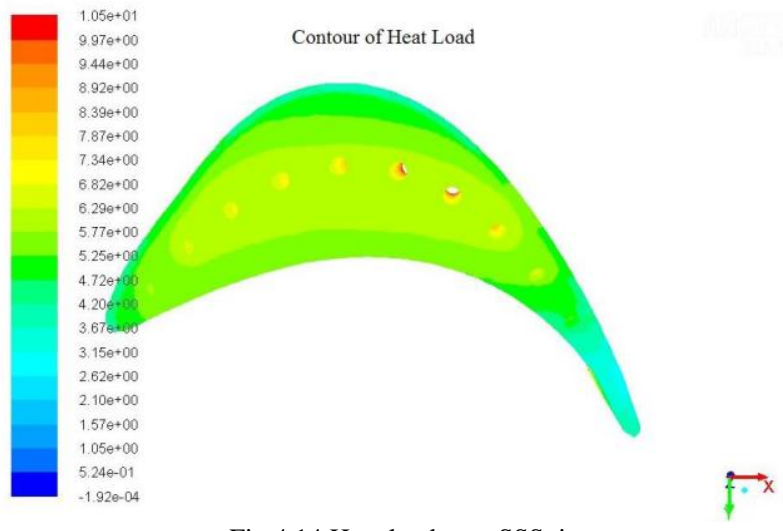

Fig 4.14 Heat load on a SSS tip

The heat load of the cooled suction-side squealer tip is higher than that of an uncooled suction side squealer tip, mainly because the heat-flux rate on the floor of the tip increases significantly. The heat load of the cooled suctionside squealer is the highest.

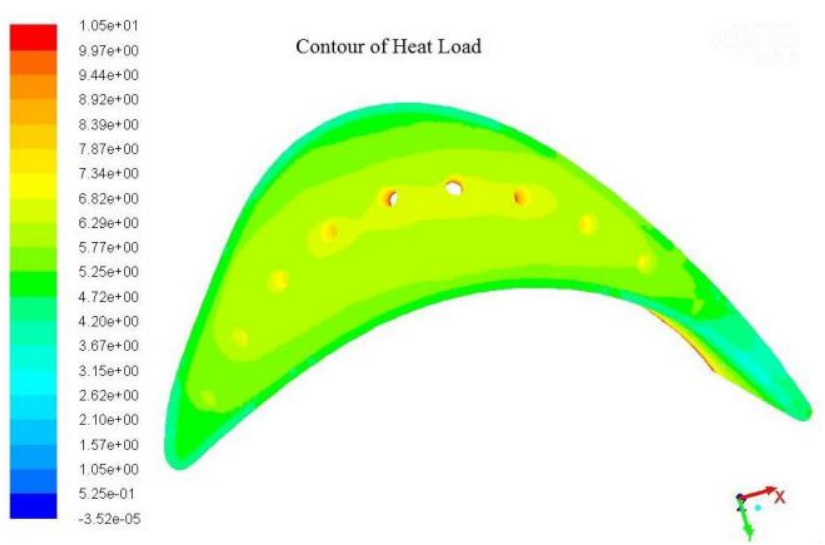

Fig 4.14 Heat load on a Cavity tip

The coolant injection on the cavity tip results in good thermal protection. The heat load of the cavity tip reduces by with coolant injection

\begin{tabular}{|l|c|}
\hline Type of Tip & Heat Load \\
\hline Flat & 0.57 \\
\hline SSS & 0.2045 \\
\hline Cavity & 0.141 \\
\hline
\end{tabular}

Table 4.3 Comparison table of Heat load

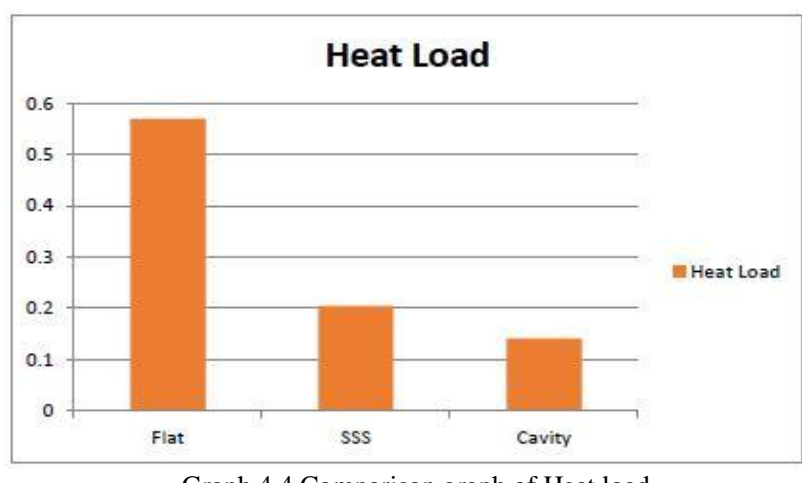

Graph 4.4 Comparison graph of Heat load

5. RESULTS OBTAINED

Effect of Heat Transfer Coefficient

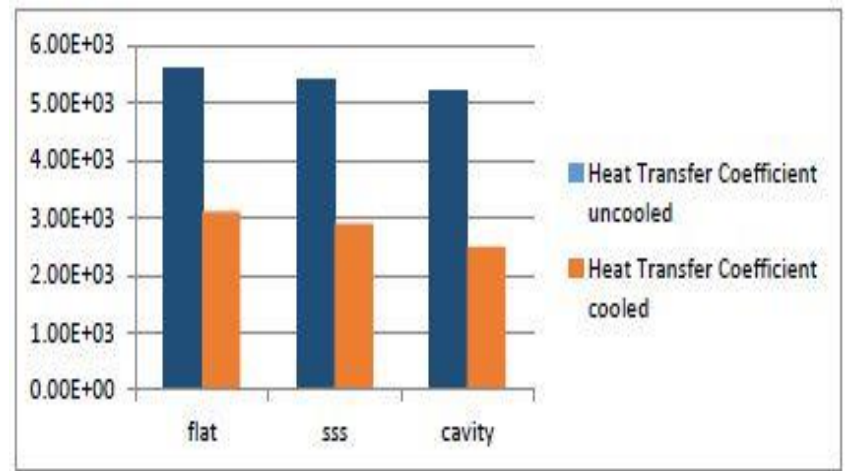

Graph 5.1 Effect of Heat Transfer Coefficient

\begin{tabular}{|l|c|c|}
\hline \multirow{2}{*}{ Type of tip } & \multicolumn{2}{|c|}{ Heat Transfer Coefficient } \\
\cline { 2 - 3 } & Uncooled & Cooled \\
\hline Flat & $5.57 * 10^{3}$ & $3.10 * 10^{3}$ \\
\hline SSS & $5.41 * 10^{3}$ & $2.90 * 10^{3}$ \\
\hline Cavity & $5.21 * 10^{3}$ & $2.49 * 10^{3}$ \\
\hline
\end{tabular}

Table 5.1 Effect of Heat Transfer Coefficient 
Effect of Net Heat Flux Reduction

\begin{tabular}{|l|c|}
\hline \multicolumn{1}{|c|}{ Type of Tip } & NHFR \\
\hline Flat & 1.12 \\
\hline SSS & 1.14 \\
\hline Cavity & 1.13 \\
\hline
\end{tabular}

Table 5.2 Effect of Net Heat Flux Reduction

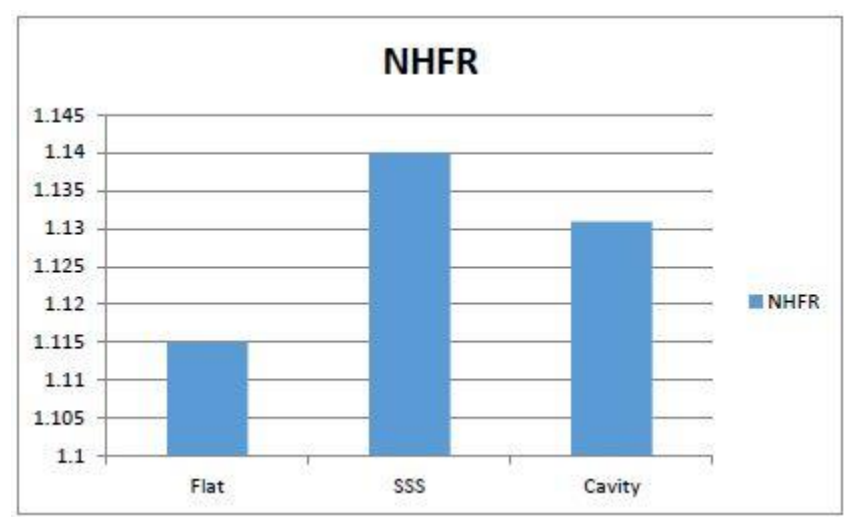

Graph 5.2 Effect of Net Heat Flux Reduction

The analysis is done for cooled flat tip, cooled SSS tip and cooled cavity tip. It is seen that SSS tip and cavity tip shows a good performance under high temperature than flat tip. For uncooled tips squealer tips had lower average heattransfer coefficients than flat tips. The use of squealer tips reduces the heat-transfer coefficient on the tip, it also increases the surface area of the tip, which may result in an increase of the heat load. The results showed that the heat load of the cavity tip lower than that of the flat tip. The cooling effectiveness varies significantly with the tip geometries and the location of the cooling holes. It is seen that discrete slots produced better thermal performance than other cooling geometries. The injection of the coolant increased the heat transfer coefficient, and if the cooling effectiveness was not low enough, the injection could actually increase the heat load on the tip.

\section{CONCLUSION}

The thermal performance of the three turbine-tip geometries were investigated using CFD. The results are presented in terms of heat-transfer coefficient, cooling effectiveness, NHFR, and heat load. The coolant flow patterns from the different cooled tips were presented. The variation of heat transfer coefficient for cooled and uncooled blades shows that, the value reduced to a huge extend on cooling. At a coolant mass flow ratio of $0.52 \%$, the cooled flat tip is cooled effectively but the cooling effectiveness of the cavity tip is higher than the cooled flat tip. The coolant ejection lifts from the floor of the suctionside squealer tip so that the cooling effectiveness is lower than that of cavity tip. The heat load of the flat tip is also higher because of its larger surface area. The cooled suction-side squealer tip has comparatively lower value of heat load than that of flat tip. Heat load is least for cavity tip. By studying different parameters affecting the performance of High Pressure turbine blade, Cooled cavity tip shows significant performance under various working condition.

\section{REFERENCE}

[1] Abhari, R. S. and Epstein, A. H., 1994, "Experimental Study of Film Cooling in a Rotating Transonic Turbine," ASME Journal of Turbomachinery, vol. 116, no. 1, pp. 63-70.

[2] Behr, T., Kalfas, A. I. and Abhari, R. S., 2008, "Control of Rotor Tip Leakage Through Cooling Injection from the Casing in a HighWork Turbine," ASME Journal of Turbomachinery, vol. 130, no. 3, pp. 1-12.

[3] Chyu, M. K., Moon, H. K. and Metzger, D. E., 1989, "Heat Transfer in the Tip Region of Grooved Turbine Blades," ASME Journal of Turbomachinery, vol. 111, no. 2, pp. 131-138.

[4] Day, C. R. B., Oldfield, M. L. G. and Lock, G. D., 2000, "Aerodynamic Performance of an Annular Cascade of Film Cooled Nozzle Guide Vanes under Engine Representative Conditions," Experiments in Fluids, vol. 29, no. 2, pp. 117-129

[5] P. W., Boyle, R. J. and Bunker, R. S., 2004, "Measurements and Predictions of Heat Transfer on Rotor Blades in a Transonic Turbine Cascade," ASME Journal of Turbomachinery, vol. 126, no. 1 , pp. 110-121.

[6] Heyes, F. J. G., Hodson, H. P. and Dailey, G. M., 1992, "The Effect of Blade Tip Geometry on the Tip Leakage Flow in Axial Turbine Cascades," ASME Journal of Turbomachinery, vol. 114, no. 3, pp. 643-651.

[7] Kost, F. H. and Holmes, A. T., 1985, Aerodynamic Effect of Coolant Ejection in the Rear Part of Transonic Rotor Blades, AGARDograph no. 390, Heat Transfer and Cooling in Gas Turbines, North Atlantic Treaty Organisation, Paper 41).

[8] Mischo, B., Behr, T. and Abhari, R. S., 2006, "Flow Physics and Profiling of Recessed Blade Tips: Impact on Performance and Heat Load," ASME Paper Number GT2006-91074. 